\title{
IT SUPPORT FOR DESCRIPTIVE GEOMETRY COURSE FOR ENGINEERING STUDENTS
}

\author{
Aleksandar Trifunović ${ }^{1}$, \\ Svetlana Čičević ${ }^{1}$, \\ Magdalena Dragović2, \\ Aleksandar Čučaković ${ }^{2}$ \\ ${ }^{1}$ Faculty of Transport and Traffic \\ Engineering, \\ University of Belgrade, Serbia \\ ${ }^{2}$ Faculty of Civil Engineering, \\ University of Belgrade, Serbia
}

\begin{abstract}
:
Constant development of IT technologies and Descriptive Geometry (DG) course time limitation pose new challenges in engineering education methodology. A wide range of supportive digital tools for knowledge transfer exist for reaching certain goals related to young engineers' spatial perception, imagination and comprehension. The combination of classic DG teaching methods and 3D software environment as a demonstration tool was tested on three generations of students. Statistical analyses based on data collected through student questionnaire have shown the benefits of 3D CAD models implementation regarding achievement and motivation, as well as the student ability to use new technology environment resources.
\end{abstract}

\section{Keywords:}

Descriptive geometry teaching/learning, 3D Auto CAD geometric models, Students' motivation, engineering education.

\section{INTRODUCTION}

In an ever-changing technological world, new educational technologies continue to emerge at a rapid pace expanding our access to new information. Information and communication technologies (ICT) represent a set of tools and applications that allow the incorporation and strengthening of new educational strategies. Many of them have been defined in new teaching frameworks during the last two decades. The interest, need, and urgency to implement new technologies in education and at universities in particular are relatively new [1]. At the same time, the exact impact of using technology for instruction is still unknown. For an educator in the 21 st century, it is important to gain a deeper understanding of the impact of technology on education [2]. New technology implementations in the teaching field have been largely extended to all types of levels and educational frameworks. One of them is the subject of this paper, Descriptive geometry (DG), as an area where 3D computer modeling and interactive software visualization can be applied with potentially significant impacts.

Young engineers' attention at the Faculty of Civil Engineering is focused on modern methods and computer aided teaching/learning processes. The first year study curriculum, in particular, intends to provide basic knowledge for developing engineering skills, such as spatial perception,
Aleksandar Trifunovic

e-mail:

a.trifunovic@sf.bg.ac.rs 
imagination, and geometric task solving relevant for future professional demands [3]. The essential knowledge includes geometric shapes and their characteristics applicable in engineering practice. These goals are assumed to be achieved in contemporary Descriptive Geometry (DG) course training [4]. As stated by Stachel in [5] "DG is a method to study $3 \mathrm{D}$ geometry through $2 \mathrm{D}$ images.... Typical for DG is the interplay between 3D situation and 2D representation". The teaching practice streamline of DG course at the Faculty of Civil Engineering relies on 3D computer environment implementation (AutoCAD software). Auto CAD have already proved its efficiency and quality for educational purposes, both in $2 \mathrm{D}$ drawings and 3D modeling [6,7]. 3D representations of spatial elements and structures in Auto CAD are aimed to complement 2D drawings (classical orthographic and isometric projections) - solutions of specific geometric tasks. However classical drawing performance on a blackboard (for teachers)/sheet of paper (for students) is not abandoned.

Several goals of 3D CAD models implementation include the possibility of direct correlation of virtual -"spatial" model and its 2D projections (view tool palette), visual perception of geometric entities (various surfaces and solids), visual contact with 3D object from any observer's point of view, (orbit command) and "step by step" guidance through task solution process (layer control), all enabled in AutoCAD.

In accordance with personal and worldwide scientific research results and discussions $[8,4,5,7,9,10]$, benefits were expected in regard to spatial reasoning and imagination, spatial abilities and DG learning motivation improvement, as well as better scores achievement. Statistical analyses were done on data collected through student's questionnaire filled in after the final exam. The sample included 130 students from the three last generations.

\section{DESCRIPTIVE GEOMETRY COURSE ORGANIZATION}

\section{Organization of lectures}

Contemporary practice of DG course lecturing during three months (two lessons per week) is not enough for complex course content. Lectures are organized ex cathedra as Power point presentations supported by printed handouts (half finished drawings), blackboard drawings and demonstrations with 3D AutoCAD models. All the lectures $\left({ }^{*}\right.$.pdf files, or ${ }^{*}$.ptt presentations) are available at the official Faculty website.

\section{Practice Organization}

Individual practice in geometric tasks solving takes part at the Faculty (one week after each lecture/topic), on a sheet drawings, assuming that students have previously studied given handouts/tasks - AutoCAD drawing files. These files contain solutions of tasks, i.e. 2D drawings (orthographic or oblique projections) and complementary 3D models (Figs. 1a- b.), being available within teaching materials panel at www.grf.bg.ac.rs.

Teaching assistant's guidance and helping during task performance are provided in "step by step" manner instructions along with discussion and simultaneous demonstration/presentation in AutoCAD. Short instructions for ${ }^{*}$. $\mathrm{dwg}$ files usage were prepared in accordance to several required Auto CAD commands and tools (Fig. 2).

\section{Descriptive geometry course organization requirements}

An adequate student's response and cooperation are assumed for information and handout collection (downloading instructions and various files from the Faculty's website), activity in software acquisition and motivation to adopt new teaching environment. Even though all traditional learning accessories are available for studying (DG handbook, printed sheets for the lectures and handbook-collection of tasks) the assumption was that new generations of students would be more familiar with new technological learning environment.

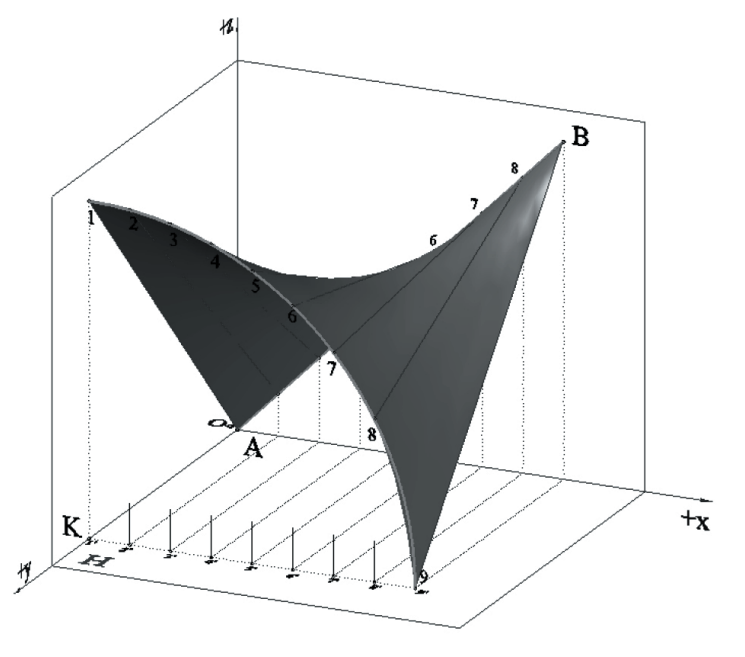

Fig. 1a. 3D model of a conoid surface. 


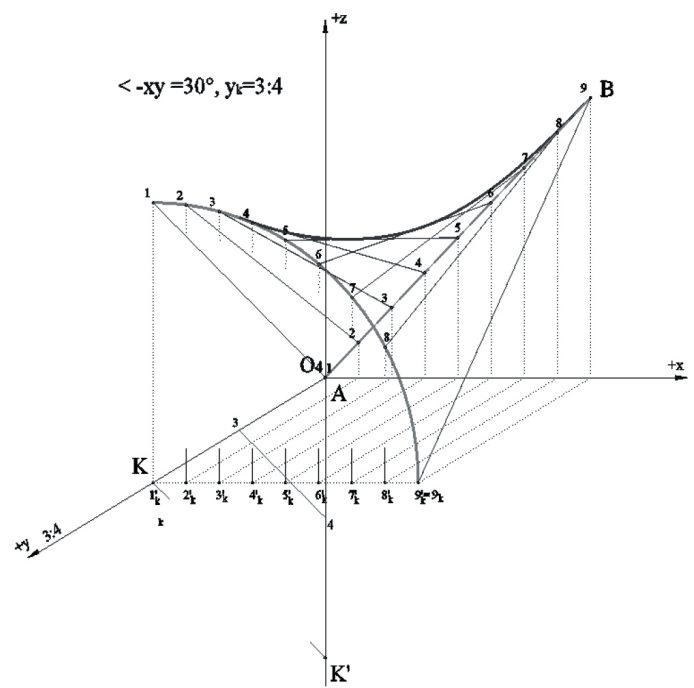

Fig. 1b. 2D drawing - oblique projection of a conoid surface.

In case of attending two corresponding courses, Engineering Graphics (where students acquire Auto CAD 2D drawing skills) and DG, a rather small number of operations (commands or tools) in Auto CAD are required.

Today, the incorporation of technology into classroom is a fact [11], though one cannot affirm that the usage of technology will lead to an increase in student motivation, satisfaction, or academic achievement. However, these innovations require approval and evaluation by the final users - students.

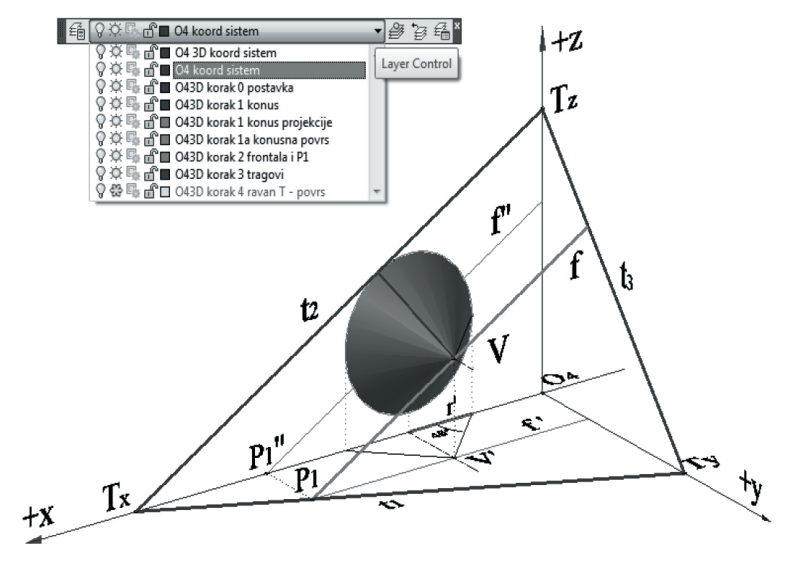

Fig. 2. Illustration of layer control related to specific geometric task.
Student experience regarding the modernization of $D G$ course

The challenge for educators is to design "prototypical characteristics" for the learning settings that encourage student motivation [12]. Motivation is commonly defined as an individual's activation and degree of persistence in undertaking goal directed behavior. According to Sanacore (2008), motivation is the key to academic success as well as promotion of lifelong learning [13]. In general, motivation is defined as the individual's desire to participate in the learning process; it involves the reasons or goals that underlie their involvement or non-involvement in academic activities [14]. Student motivation is determined by their willingness and volition. Intrinsic motivation is animated by personal enjoyment, interest, or pleasure, while extrinsic motivation is dominated by reinforcement contingencies [15]. However, being motivated to learn refers to the degree to which students are dedicated to and engaged in learning. Engagement is critical, because the level of engagement over time is the vehicle through which classroom instruction influences student outcomes [16, 17]. When an individual's motivation is high - i.e., there is high activation, persistence, and goal directed behavior - achievement and performance of that individual will be great as well $[18,19]$. In that regard, high subject interest could produce high levels of self reported motivation.

In order to measure the efficiency of the teachinglearning process during the semester, a survey was conducted regarding student perception. The aim was to evaluate the degree of adaptation to and satisfaction with the introduction of computer-aided teaching of DG, as well as the advantages of working with new technology environment resources. The feedback process based on data provided by students is of particular relevance, as it will bring about active modification of the methodology for future iterations of the process of classroom instruction.

\section{METHODOLOGY}

The total sample included 130 first year students attending DG course at the Faculty of Civil Engineering, University of Belgrade. Data were collected from the three generations of civil engineering students (2014-2016) who were monitored and inquired after the final exam.

Paper-based questionnaire (formulated by the lecturers for the purpose of this study) was filled in after the first examination term. The data were loaded and processed in a database made in MS Excel. Statistical analysis was 
performed using the statistical software package IBM SPSS Statistics v. 22. Normality of distribution was tested by Frequency histograms and the Kolmogorov-Smirnov test. Since the distribution of all interval variables significantly deviate from the normal distribution, the nonparametric tests were employed. To assess whether there are significant differences among two or more variables Kruskal-Wallis's tests were performed. To test the strength and direction of the linear relationship between variables Spearman's rank correlation $(\rho)$ was calculated.

\section{RESULTS}

Based on the student responses, the overall outcome of the usage of AutoCAD is positive.

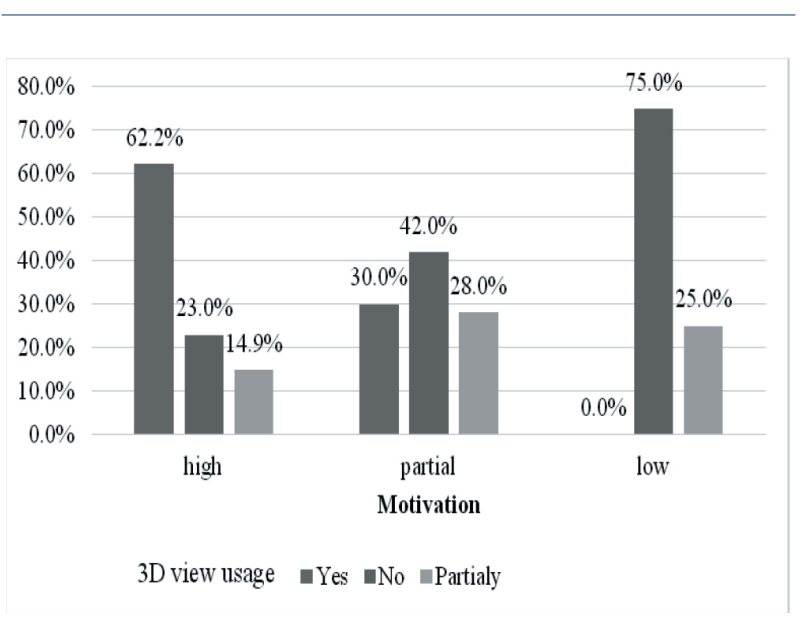

Fig. 3. Student motivation in respect to $3 \mathrm{D}$ view option usage.

Kruskal-Wallis's test show statistically significant differences in student motivation between those who used $3 \mathrm{D}$ view option in AutoCAD ( $\chi 2=13.395 ; \mathrm{p}=0.001)$ and those who encountered only traditional approach in solving geometrical problems (TABLE I). The results suggest that students who used 3D view option exhibit greater motivation in comparison to those who used it either partially or did not use this option at all (Fig. 3).

Furthermore, there are significant differences in learners motivation between those who show desire for acquiring further knowledge in $3 \mathrm{D}$ graphics implementing $(\chi 2=6.271 ; p=0.043)$ (Table I) and students who are not interested in engaging with new technology and have no desire and willingness to deploy effort toward better task completion.

Students who have greater desire for further improvement of their mastery with 3D geometry graphics exhibit higher motivation in comparison to those who show no interest to try new functions and use interactive 3D models (Fig. 4).

As expected, motivation has positive impact on academic performance of students. There is positive relationship between student motivation and their academic performance. The results suggest that students who are highly motivated received higher exam scores in comparison to those who reported moderate or low motivational level $\left(\chi^{2}=13.929 ; \mathrm{p}=0.001\right)$ (Table 1.).

\begin{tabular}{cccc}
\hline & $\begin{array}{c}\text { 3D view } \\
\text { option in } \\
\text { AutoCAD } \\
\text { usage }\end{array}$ & $\begin{array}{c}\text { Desire for } \\
\text { further } \\
\text { improvement } \\
\text { of work with } \\
\text { 3D graphics }\end{array}$ & Exam scores \\
\hline Chi-Square & 13.395 & 6.271 & 13.929 \\
\hline df & 2 & 2 & 2 \\
\hline Asymp. Sig. & 0.001 & 0.043 & 0.001 \\
\hline
\end{tabular}

Table 1. Student motivation regarding 3D option usage, engagement and achievement.

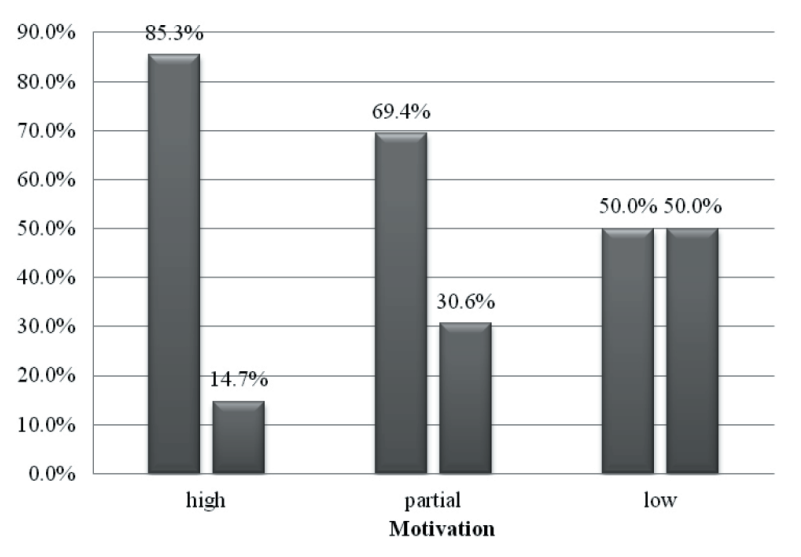

$\square$ Have desire for further improvement $\quad$ No desire for further improvement

Fig. 4. Differences in student motivation and desire for further improvement of knowledge in 3D graphics.

The linear regression results offer further insight into the relationship between student motivation and their academic achievement (Fig. 5).

Spearman's rank-order correlation was run to determine the relationship among student motivation and 3D computer environment implementation (3D mode in AutoCAD and $3 \mathrm{D}$ view option in AutoCAD usage) and desire for further improvement of work with 3D graphics (TABLE II). Students who show higher motivation levels are more prone to use $3 \mathrm{D}$ mode, as well as $3 \mathrm{D}$ view option in AutoCAD. Higher motivation is also accompanied with 
stronger desire for further improvement of knowledge and work with 3D graphics.

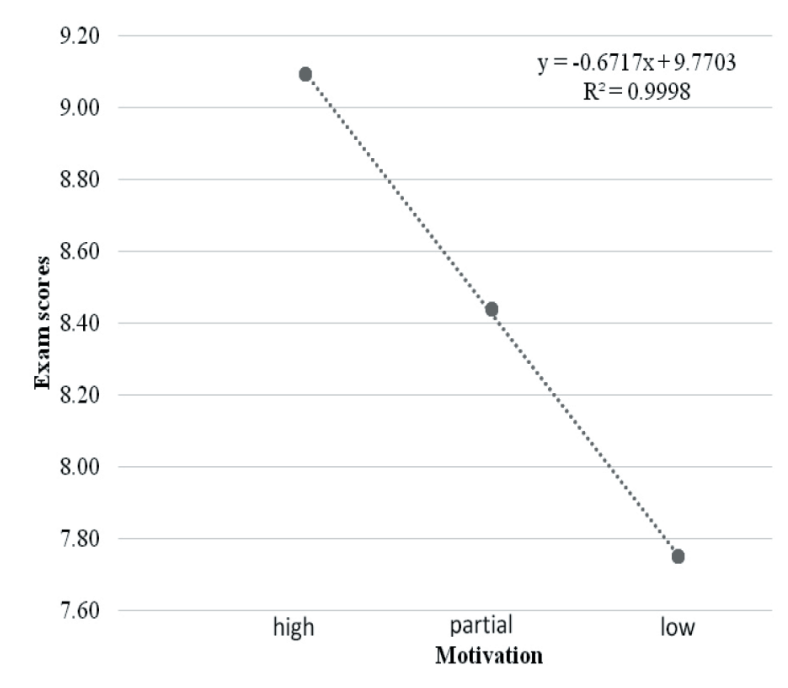

Fig. 5. Relationship between student motivation and achievement.

\begin{tabular}{cccc}
\hline & $\begin{array}{c}\text { 3D mode in } \\
\text { AutoCAD } \\
\text { usage }\end{array}$ & $\begin{array}{c}\text { 3D view } \\
\text { option in } \\
\text { AutoCAD } \\
\text { usage }\end{array}$ & $\begin{array}{c}\text { Desire for } \\
\text { further } \\
\text { improvement } \\
\text { of work with } \\
\text { 3D graphics }\end{array}$ \\
\hline $\begin{array}{c}\text { Spearman's } \\
\text { Correlation }\end{array}$ & $0.182^{\star}$ & $0.287^{* *}$ & $0.177^{\star}$ \\
\hline Sig. (2-tailed) & 0.033 & 0.001 & 0.045 \\
\hline
\end{tabular}

Table 2. Relationship among student motivation, 3D computer environment usage and desire for knowledge improvement.

\section{DISCUSSION}

The research results have clearly shown the benefits of 3D CAD models implementation in terms of achievement and motivation, as well as the student ability to use new technology environment resources. 3D computer modeling is also an efficient tool in innovation regarding teaching of geometry and the achievement of better results. Introduction of modern software packages in Descriptive Geometry improves the quality of studies, while students become more involved and interested.

Students are of the opinion that new teaching materials help them to understand the content of the course more easily. 3D CAD models usage is associated with high levels of reported motivation and promotes desire for acquiring further knowledge. Students who used AutoCAD were more motivated to learn Descriptive Geometry, which became one of the more popular courses. In spite of the fact that 3D CAD models usage is significantly related with higher motivational levels, those correlations were relatively weak. Therefore, it is very important to gain insight in the most relevant aspects of student experience regarding what should be improved both in future interactions and technological innovations within a teaching framework.

\section{REFERENCES}

[1] D.L. Rogers, A paradigm shift: "Technology integration for higher education in the new millennium," Educ. Technol. Rev, pp. 19-27, 2000.

[2] M. Granito, and E.Chernobilsky, "The Effect of Technology on a Student's Motivation and Knowledge Retention," NERA Conference Proceedings, http://digitalcommons.uconn.edu/nera_2012/17.

[3] A. Cucakovic, M. Dimitrijevic, and B. Popkonstantinovic, "General and specific topics in Descriptive Geometry and Engineering Graphics education," in Proceedings of $23^{\text {rd }}$ Int. Sci.Conf. on Geometry and Graphics "MoNGeometrija 2006," Novi Sad, pp. 199-209, 2006.

[4] R. Migliari, "Descriptive Geometry: From its past to its future," Nexus Netw J, vol. 14, 3, pp. 555-571, 2012.

[5] H. Stachel, "The role of Descriptive Geometry in the different curricula, "Int. Sci.Conf. on Geometry and Graphics "MoNGeometrija 2010,"Belgrade,2010. https://pdfs.semanticscholar.org/3c40/ 6bc01fcda0b886e04ceb7025afbb4 ee67b0f.pdf

[6] R. Knezevic, AutoCAD Tasks 2D - Architecture and Civil Engineering, Handbook (AutoCAD zadaci, 2D priručnik za arhitekturu i građevinarstvo), Zavod za udzbenike, Beograd, 2007.

[7] E. Kozniewski, and M. Orlowski, "From 2D Mongean projection to 3D model in AutoCAD, " J. Polish Soc. Geom. Engrg. Graph, vol. 22, pp. 49-54, 2011.

[8] A. Cucakovic, and B. Jovic, "Optional course Engineering Graphics on Department of Lendscape Architecture in the Faculty of Forestry - University of Belgrade," in Proceedings of $2^{\text {nd }}$ Int. Sci.Conf. on Geometry and Graphics "MoNGeometrija 2010," Belgrade, pp. 61-67, 2010.

[9] M. Mitic, A. Cucakovic and B. Jovic, "Proposals for advanced application of Descriptive Geometry in education process at the Department of Lendscape Architecture in the Faculty of Forestry - University of Belgrade," in Proceedings of $1^{\text {st }}$ Int. Sci.Conf. on Geometry and Graphics "MoNGeometrija 2008," Nis, pp. 187-198, 2008. 
[10] K. Suzuki,"Traditional descriptive geometry education in 3D- CAD/CAG era," J. Geom. Graph, vol. 18, 2, pp. 249-258, 2014.

[11] C. Dede, "Emerging influences of information technology on school curriculum, "J. Curriculum Stud, pp. 32, 2, pp. 281-303, 2000.

[12] S. Paris and J. Turner, "Situated motivation", in Student motivation, cognition, and learning, P. Pintrich, D. Brown, and C.E. Weinstein, Eds. Hillsdale, NJ: Lawrence Erlbaum Associates, 1994, pp. 213237.

[13] J. Sanacore, "Turning Reluctant Learners into Inspired Learners, "Clearing House: A J Educ Strateg, Issues and Ideas, vol. 82, 1, pp. 40-44, 2008.

[14] P. C. Dev, "Intrinsic motivation and academic achievement," Remedial Spec. Educ, vol. 1, pp. 1219, 1997.
[15] Z. Mahdikhani, and Z., Iran "An Overview of Motivation: The Challenges and the Importance of Motivation for Second Language Acquisition", J. Stud. Eng. Linguist, vol. 4, 1, pp. 53-59, 2016.

[16] J. Irvin, J. Meltzer, and M. Dukes, “Taking Action on Adolescent Literacy: An Implementation Guide for School Leaders“, ASCD, Alexandria, 2017.

[17] V. Trowler, "Student engagement literature review", The Higher Education Academy, York Science Park, 2010.

[18] W. R. Adler, J. M. Milne, and R. Stablein, "Situated Motivation: An Empirical Test in an Accounting Course," Can. J. Adm. Sci, 18, pp. 101-115, 2001.

[19] S. Graham, and B. Weiner, "Theories and principles of motivation", in Handbook of educational psychology, D. C. Berliner and R. Calfee, Eds. Macmillan, New York, pp. 63-84, 1996. 